\title{
UTILIZANDO A LUDICIDADE NO ENSINO DE CIÊNCIAS EM UMA ESCOLA PÚBLICA DE PORTO ALEGRE: O FAZER DOCENTE CONTEXTUALIZADO E INTEGRADO ALÉM DA SALA DE AULA
}

\author{
Gabriela Dipicoli Brasil* \\ Silvia Vieira München ${ }^{* *}$ \\ Cibele Schwanke***
}

\begin{abstract}
Resumo: Atualmente há diversos casos relacionados às doenças transmitidas pelo mosquito Aedes aegypti, reforçando a validade de sua contextualização no ensino de ciências. Visando demonstrar aos licenciandos em Ciências da Natureza do IFRS a pertinência de utilização do espaço escolar para além da sala de aula e capacitá-los na organização de eventos científicos em unidades escolares, em 2016, desenvolveu-se o evento de extensão "Todos contra o Aedes aegypti". A ação ocorreu em uma escola pública de Porto Alegre envolvendo duas turmas do $7^{\circ}$ ano do Ensino Fundamental e permitiu abordagens interdisciplinares, contemplando aspectos relacionados à história, tecnologia, saúde e meio ambiente. Durante a intervenção, desenvolveu-se uma dinâmica ambiental em forma de jogo, enfatizando aspectos relacionados à proliferação do inseto. Baseou-se em material informativo divulgado pela Prefeitura de Porto Alegre, pesquisas relacionadas ao tema e ao uso de jogos educativos e produção de material testado com licenciandos. A avaliação por parte dos estudantes e professora regente da unidade escolar foi considerada a melhor no evento. Além de abordar a importância da prevenção de doenças, percebe-se a relevância da ludicidade, criando momentos de interação, integração, desenvolvimento crítico e construção de saberes significativos e contextualizados relacionados à saúde e ao ensino de ciências.
\end{abstract}

Palavras-chave: Ciências. Meio Ambiente. Extensão. Ludicidade. Aedes

\section{Introdução}

O mosquito Aedes aegypti é um assunto recorrente no Brasil, principalmente na temporada de verão, quando as chuvas são constantes, as temperaturas mais elevadas e a incidência das doenças associadas cresce significativamente. As patologias causadas por esse vetor representam um problema de saúde pública, pelo fato de sua rápida proliferação, dos riscos à saúde e pelos gastos públicos (OLIVEIRA, 2013). Considerando que a informação é

\footnotetext{
* Acadêmica do Curso de Licenciatura em Ciências da Natureza - Habilitação em Biologia e Química do Instituto Federal de Educação, Ciência e Tecnologia do Rio Grade do Sul - campus Porto Alegre.

** Acadêmica do Curso de Licenciatura em Ciências da Natureza - Habilitação em Biologia e Química do Instituto Federal de Educação, Ciência e Tecnologia do Rio Grade do Sul - campus Porto Alegre.

**** Doutora em Ciências (UFRGS) e docente do Instituto Federal de Educação, Ciência e Tecnologia do Rio Grande do Sul - campus Porto Alegre
} 


\section{\#tear}

importante, visto que também é compromisso da população evitar a proliferação do mosquito, adotando medidas que ajudem na redução e contaminação do transmissor, entende-se que o espaço escolar possibilita um lócus para oportunizar momentos de aprendizagem, contribuindo para a solução desse problema em esfera nacional.

Cientes dessa realidade, o presente trabalho relata um evento de extensão organizado por alunos de Licenciatura em Ciências da Natureza do Instituto Federal de Educação, Ciência e Tecnologia do Rio Grande do Sul - campus Porto Alegre (IFRS), onde foram abordados, de forma interdisciplinar, aspectos relacionados à prevenção de doenças e combate deste vetor, utilizando a ludicidade no Ensino de Ciências enquanto instrumento para contextualização, aproximação e envolvimento dos participantes.

\section{Contextualizando a prática educativa}

Os documentos orientadores elaborados pelo Ministério da Educação, em sua concepção, destacam a interdisciplinaridade e a contextualização como fundamentais para a efetivação de processos de ensino e de aprendizagem significativos, de forma a evitar a fragmentação curricular (GARCIA, 2008). Os Parâmetros Curriculares Nacionais (PCNs), destacam na área de conhecimento Ciências da Natureza que, para realizar a ênfase da saúde enquanto um estado de equilíbrio dinâmico do corpo e um bem coletivo, é fundamental a realização de abordagens diversificadas e em diferentes momentos (BRASIL, 1998). Além disso, propõem a criação de espaços de interlocução com temas emergentes da atualidade, destacando-se, nesse contexto, os temas transversais Saúde e Meio Ambiente. A Base Nacional Comum Curricular (BNCC), em vigor desde 2017, por sua vez, destaca os aspectos relativos à saúde, compreendida como um bem da coletividade, abrindo espaços para discussão e, com isso, promover a saúde individual e coletiva, inclusive no âmbito das políticas públicas (BRASIL, 2017).

Como destacado por Gadotti (2005), a escola caracteriza-se como um espaço de educação formal, onde currículos e sistemas de aprendizagem orientam o percurso formativo dos educandos, fortemente marcados pela sequencialidade e formalidade. No entanto, configura-se também em um profícuo espaço para a prática de educação não-formal, possibilitando a ocorrência de formas de ensino e de aprendizagem diferenciadas:

Na educação não-formal, a categoria espaço é tão importante como a categoria tempo. O tempo da aprendizagem na educação não-formal é flexível, respeitando as diferenças e as capacidades de cada um, de cada uma. Uma das características da 
educação não-formal é sua flexibilidade tanto em relação ao tempo quanto em relação à criação e recriação dos seus múltiplos espaços. (GADOTTI, 2005, p.2)

Dessa forma, o ambiente escolar pode ser visto sob diferentes perspectivas oportunizando o desenvolvimento de processos educativos em contextos de aprendizagem distintos. Partindo-se do pressuposto de que cada contexto de aprendizagem se estabelece dentro de uma rede de relações de um espaço/tempo vivido e que possui uma relação retroativa com outros contextos de aprendizagem que proporcionam a formação dos sujeitos envolvidos (TRISTÃO; FASSARELLA, 2007), entende-se que os professores de ciências precisam estar aptos a reconhecerem estes espaços visando o desenvolvimento de práticas educativas interdisciplinares e transversais.

O saber se constrói e se representa a partir das experiências vivenciadas e é no contexto do real, do fazer, que o ser humano se constitui a cada momento. Nesse contexto, a extensão acadêmica emerge como um campo de aprendizado que, atrelado ao ensino e à pesquisa e inovação sustentam as instituições formadoras em nível superior:

A Extensão Universitária é o processo educativo, cultural e científico que articula o Ensino e a Pesquisa de forma indissociável e viabiliza a relação transformadora entre a Universidade e a Sociedade (FÓRUM..., 1999).

A Lei $n^{\circ}$ 13.005/2014, ao estabelecer o Plano Nacional de Educação/PNE, destaca, na estratégia 12.7, a relevância da extensão enquanto atividade acadêmica e formativa ao:

[...] assegurar, no mínimo, $10 \%$ (dez por cento) do total de créditos curriculares exigidos para a graduação em programas e projetos de extensão universitária, orientando sua ação, prioritariamente, para áreas de grande pertinência social. (BRASIL, 2014, p. 74).

Considerando as premissas básicas da extensão, quais sejam: a relação dialógica com a comunidade, a participação efetiva de acadêmicos, a formação cidadã, a interdisciplinaridade e interprofissionalidade, e a indissociabilidade ensino-pesquisa-extensão e que a formação de professores em ciências prevê o reconhecimento da dimensão do fazer docente na criação, no planejamento, na realização e na gestão da prática de ensino de Ciências da Natureza, avaliando situações escolares com relação ao conhecimento, às escolhas metodológicas, à avaliação da aprendizagem e ao ambiente de trabalho, desenhou-se uma proposta extensionista por licenciados matriculados na componente curricular Vivência Docente Compartilhada I do Curso de Licenciatura em Ciências da Natureza do IFRS - Campus Porto Alegre. 


\section{\#tear}

\subsection{Caracterização da intervenção}

Como toda a ação extensionista preconiza, o planejamento da ação teve como ponto de partida a identificação de demandas. Para tanto, cada licenciando entrou em contato com uma unidade escolar que manifestou interesse (ou não) em participar da intervenção, identificando os níveis de ensino (Fundamental ou Médio) e os anos de escolaridade, além das temáticas emergentes. O tema recorrente foi saúde e considerando o aumento da incidência dos casos das doenças transmitidas pelo mosquito Aedes aegypti, percebeu-se a necessidade de apresentar seus riscos e suas formas de prevenção, utilizando-se a ciência como base para a abordagem contextualizada. Nesse sentido, definiu-se a organização de um encontro direcionado à comunidade escolar que possibilitasse a troca de experiências e reflexões acerca desta problemática, mediante uma abordagem multidisciplinar e diversificada, envolvendo aspectos relacionados à história, tecnologia, saúde e ambiente.

Nesse âmbito, definiu-se que a abordagem envolveria demonstrar como o mosquito Aedes aegypti se dispersou pelo mundo; compreender a origem das terminologias relacionadas às patologias provocadas pelo mosquito Aedes aegypti; apresentar os sintomas provocados pelas doenças causadas pelo Aedes aegypti, contextualizando as doenças e os possíveis tratamentos; identificar os métodos de prevenção e de combate à proliferação do mosquito Aedes aegypti, e refletir sobre a relação homem e meio ambiente no que diz respeito à saúde pública, com especial atenção à dengue, zika e chikungunya.

\subsubsection{A importância da ludicidade no ensino de ciências}

A escola tem como objetivo principal formar cidadãos conscientes, críticos e dispostos a enfrentar diversas situações no seu cotidiano. No entanto, há barreiras que precisam ser vencidas pelos professores, como a falta de motivação dos alunos na sala de aula e a fragmentação curricular. Nesse sentido, é necessária a inserção de métodos diferenciados de ensino, que façam com que a aprendizagem do aluno seja satisfatória (MELLO et al., 2015).

Muitos professores utilizam o método tradicional de ensino, caracterizada pela transmissão de conteúdos por parte do professor e passividade dos alunos. Assim, pelo fato do ensino de Ciências envolver conteúdos abstratos e de difícil compreensão, prevalece na prática educativa a memorização e a recepção por parte do discente, não havendo uma ligação com o cotidiano em que vivem (LEPIENSKI; PINHO, 2013).

Nesse sentido, a ludicidade configura-se em uma ótima possibilidade de contribuição na trajetória escolar dos alunos, pois é um grande facilitador de aprendizagem, permitindo a 


\section{\#tear}

criação de espaços e momentos onde os alunos sintam-se motivados, possibilitando o estabelecimento de relações do conteúdo abordado com o seu dia a dia, de forma prazerosa e participativa. Como ressaltado por Rolim (2008), o brincar é a relação com a aprendizagem, é aprender. O lúdico torna-se uma proposta educacional para o enfrentamento das dificuldades do processo de ensino e aprendizagem, salientando que:

\footnotetext{
O brincar prepara para futuras atividades de trabalho: evoca atenção e concentração, estimula a auto-estima e ajuda a desenvolver relações de confiança consigo e com os outros. Colabora para que a criança trabalhe sua relação com o mundo, dividindo espaços e experiências com outras pessoas (ROLIM, 2008, p. 177).
}

Nesse sentido, a ludicidade pode ser contemplada em diversos conteúdos de Ciências, como os assuntos relacionados ao mosquito Aedes aegypti. Nesse contexto, sabendo que as doenças causadas por esse vetor são um problema de saúde pública, a prevenção requer ações que envolvam toda a população. Sendo assim, a intervenção por parte da escola pode ser uma contribuição para relacionar o mosquito e suas doenças no cotidiano dos alunos (OLIVEIRA, 2013).

A partir disso, sabendo dos diversos casos relacionados a doenças provocadas pelo presença do mosquito, reforça-se a necessidade de contextualização dessa problemática atual no ensino de Ciências. Com isso, foi realizado o evento de extensão "Todos contra o Aedes aegypti", cuja finalidade foi abordar as particularidades históricas, tecnológicas, ambientais e de saúde pública relacionadas ao tema.

\subsection{O evento "Todos contra o Aedes aegypti!"}

O evento de extensão "Todos contra o Aedes aegypti!" foi realizado no ano de 2016, pela turma do curso de Licenciatura em Ciências da Natureza - Habilitação em Biologia e Química do Instituto Federal de Educação, Ciência e Tecnologia do Rio Grande do Sul campus Porto Alegre. A ação foi realizada em uma escola pública de Porto Alegre, com duas turmas de $7^{\circ}$ ano de ciências do Ensino Fundamental. A finalidade deste evento, a partir das demandas identificadas e da abordagem interdisciplinar planejada, contemplou abordagens com relação ao mosquito transmissor de doenças como a dengue, a chikungunya, a zika e a febre amarela. $\mathrm{O}$ evento contou com quatro eixos: história, tecnologia, saúde e meio ambiente. Cada eixo tinha duração de 50 minutos. Primeiramente, todos os alunos receberam um cartão presença (que simulava uma carteira de vacinação), na qual, eram marcadas as participações em cada eixo (Figura 1). Este "cartão de vacinação" permitiu o acompanhamento dos estudantes pelos módulos, permitindo que todos pudessem ter oportunidade de vivenciar cada 
momento do evento.

Figura 1 - Cartão de participação dos alunos.

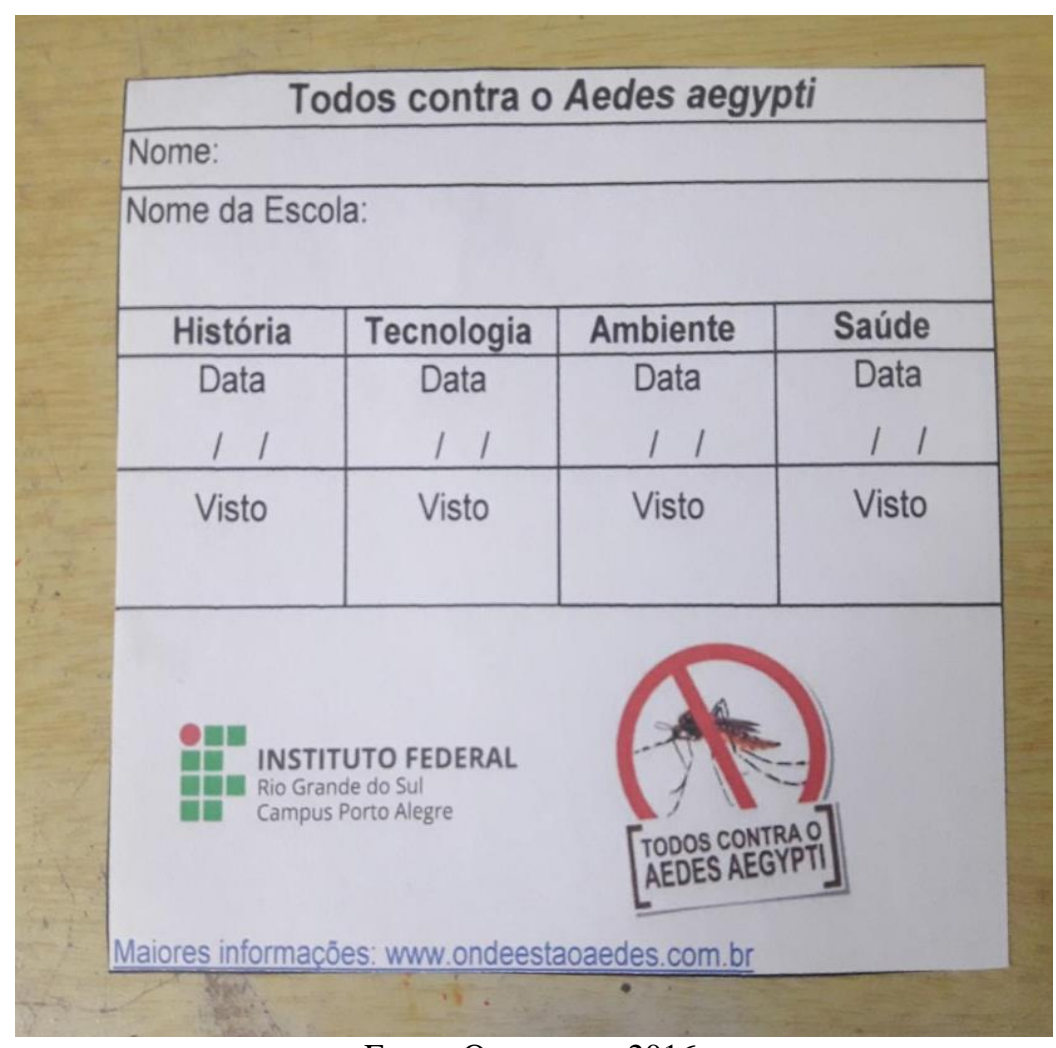

Fonte: Os autores, 2016.

\subsubsection{Eixos história, saúde e tecnologia}

Para a compreensão dos aspectos históricos e geográficos, a origem dos nomes e a história da dispersão do mosquito Aedes Aegypti, utilizou-se como recurso a exibição do vídeo “A dengue em nossa história", produzido pela Prefeitura de Recife, que apresenta a trajetória do mosquito em diversos continentes até chegar ao Brasil. Após a exibição, foi realizado um debate entre os mediadores e os alunos.

No âmbito da saúde, buscou-se abordar, de forma lúdica, os aspectos relacionados aos sintomas e à ação das doenças provocadas pelo Aedes aegypti no organismo humano. Para tanto, utilizou-se um "varal didático" com as informações dos sintomas e imagens do mosquito e das doenças, montado com a efetiva participação dos alunos.

No eixo tecnologia demonstrou-se como ela pode contribuir na redução de casos de doenças transmitidas pelo Aedes aegypti, abordando como principal tópico, as vacinas e os medicamentos, além de outras tentativas que vêm sendo desenvolvidas. 


\section{\#tear}

\subsubsection{Eixo ambiente}

O eixo ambiente foi proporcionado por dois momentos: a abordagem das questões relacionadas aos outros eixos anteriormente citados e à dinâmica ambiental, em forma de jogo, confeccionado com material alternativo e de baixo custo.

Primeiramente, foram destacadas algumas questões relacionando o que os alunos já tinham visto anteriormente nos outros eixos, visando a aplicação da Dinâmica Ambiental. Esta dinâmica teve como objetivo desenvolver os conceitos e as diferentes abordagens referentes ao mosquito Aedes aegypti na forma de um jogo. A ideia surgiu a partir de um folheto informativo da Prefeitura Municipal de Porto Alegre e pesquisas relacionadas ao tema.

\subsubsection{Metodologia da dinâmica ambiental}

A dinâmica ambiental em forma de jogo constituiu-se em uma trilha de EVA, simulando as casas (Figura 2). No decorrer da trilha, foram colocados obstáculos, como vasos de plantas com água, garrafas mal posicionadas que poderiam conter água parada, simulando o que acontece no ambiente e que geralmente são focos potenciais para a proliferação do mosquito Aedes aegypti. A partir disso, toda a dinâmica foi pensada como forma de promover a interação entre os alunos de ambas as turmas. Para representar cada jogador, foram utilizadas garrafas pet customizadas com areia colorida (Figura 3), e cards com questões relacionadas aos focos e à proliferação do mosquito.

Figura 2 - Trilha feita de EVA.

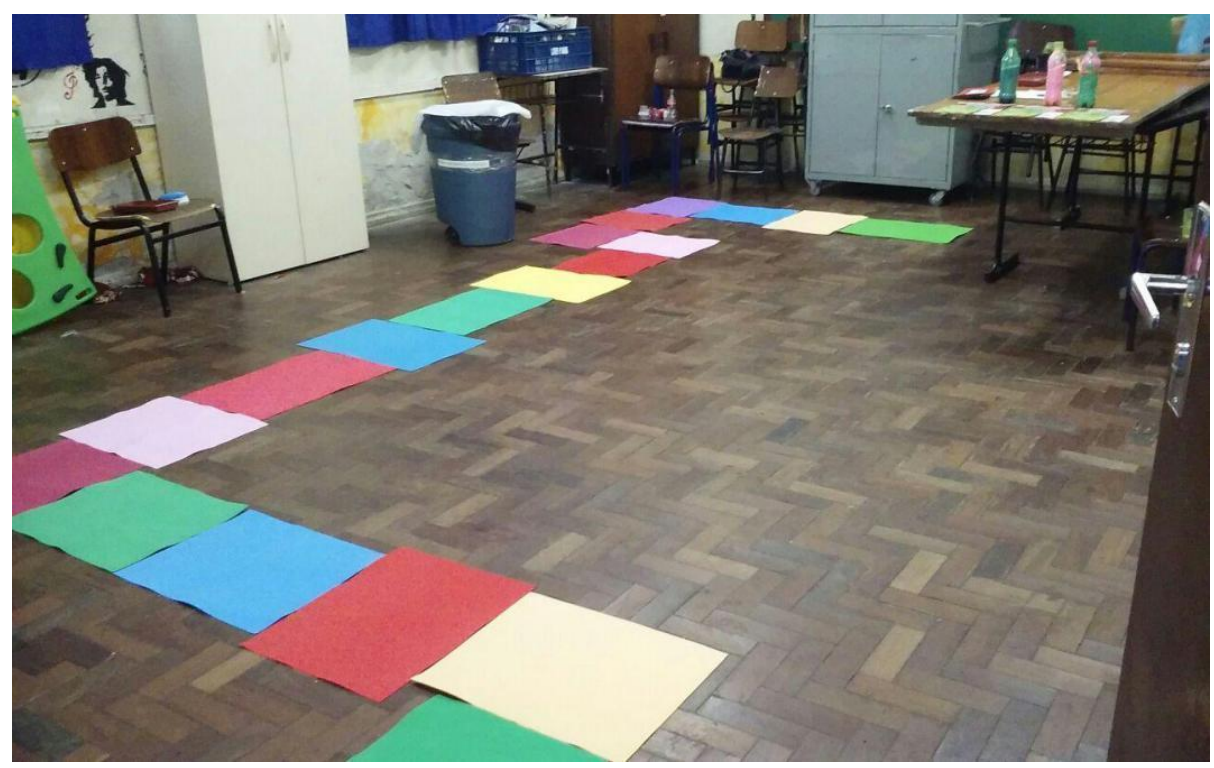

Fonte: Os autores, 2016. 
Figura 3 - Pinos de garrafa pet personalizados.

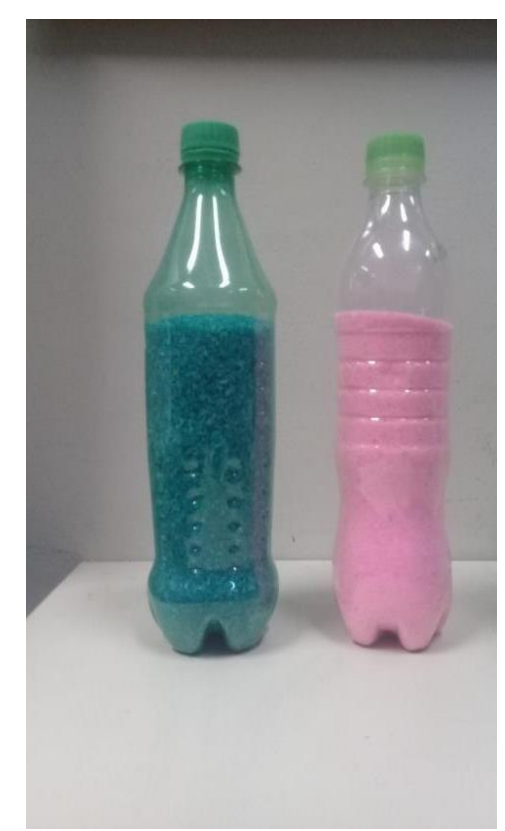

Fonte: Os autores, 2016.

Participaram desta atividade duas turmas de $7^{\circ}$ ano, com cerca de 15 (quinze) alunos por turma. Cada turma escolheu dois representantes que ficaram responsáveis por jogar o dado e outro por avançar nas casas (Figura 4). O restante das equipes deveriam auxiliar para resolver os desafios propostos nos cards, como, por exemplo, encher os pratos de plantas com areia, colocar as garrafas com a borda para baixo, despejando a água parada e escovar os pratos dos vasos das plantas para retirar as possíveis larvas que poderiam estar presentes.

Figura 4 - Dado utilizado no jogo confeccionado com caixa de leite e EVA.

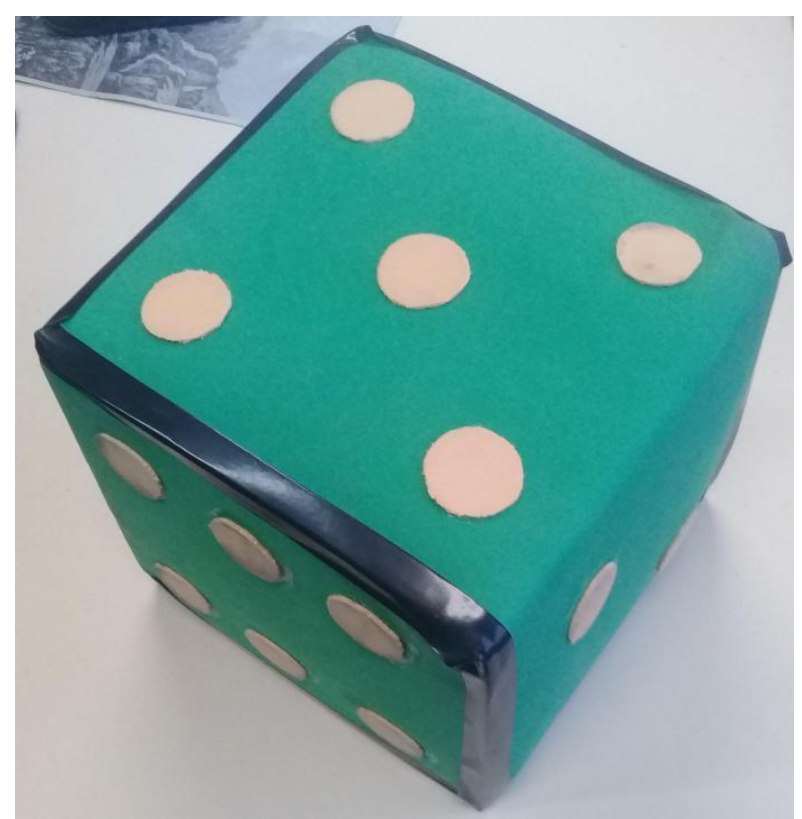

Fonte: Os autores, 2016. 


\section{\#tear}

Ao jogar o dado, dependendo do número exibido, os alunos deveriam colocar o pino sobre o EVA e as mediadoras da dinâmica realizaram a leitura dos cards com as questões referente aos focos do mosquito (Figuras 5). O aluno que estava com o pino de garrafa pet tinha que responder a questão, com o auxílio dos seus colegas. Todas as perguntas dos cards apresentavam desafios, como, por exemplo, calhas com sujeiras, garrafas, objetos e pratos de vasos de plantas com água, mostrado situações potenciais para a proliferação dos mosquitos por poderem conter suas larvas. Quem conseguisse resolver tais desafios, avançava uma ou mais casas, de acordo com a questão.

Figura 5 - Cards utilizados com informações sobre a proliferação do mosquito.

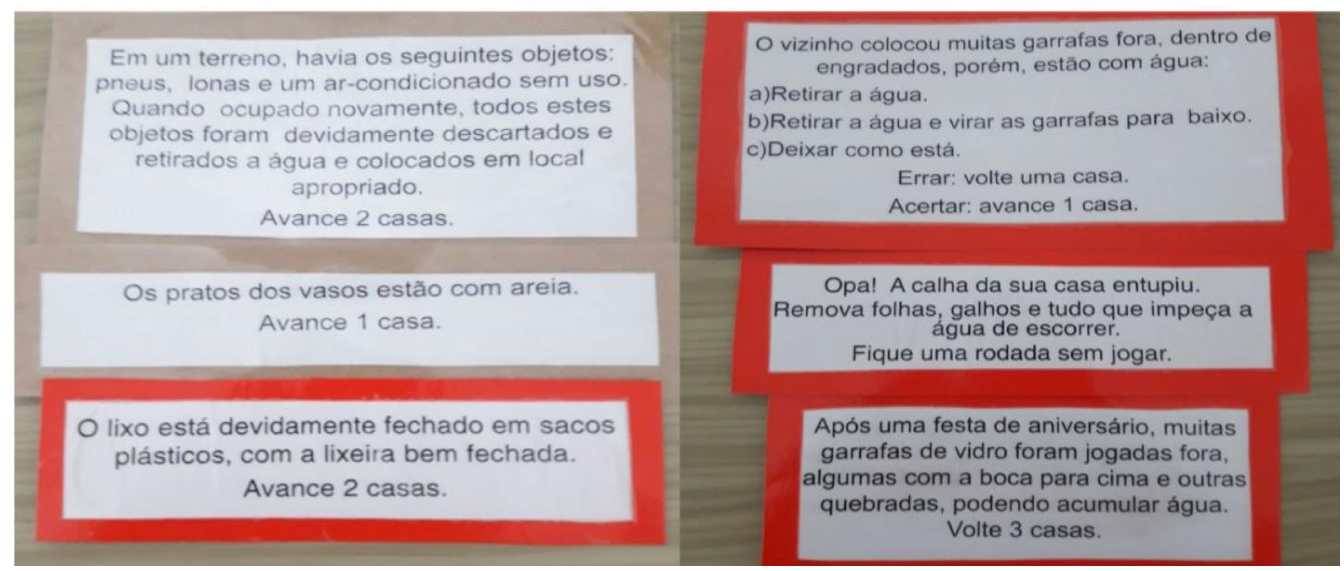

Fonte: Os autores, 2016.

\subsection{Resultados}

Ao término do evento, os alunos das duas turmas se reuniram junto à professora regente da disciplina de Ciências para responderem à pesquisa de satisfação com questões objetivas e discursivas (Figura 6). Este formulário de avaliação teve como objetivo verificar a opinião dos alunos e da professora acerca do evento, no seu aspecto geral, além de sugestões. 
Figura 6 - Pesquisa de satisfação

Avaliação

"Todos contra o Aedes aegypti!"

\begin{tabular}{|l|l|l|l|}
\hline $\begin{array}{l}\text { Para cada pergunta, marque a carinha } \\
\text { que melhor representa sua resposta }\end{array}$ & $\odot$ & $\ddots$ & $\ddots$ \\
\hline Como se sentiu ao saber do evento? & & & \\
\hline $\begin{array}{l}\text { Como se sentiu ao participar das } \\
\text { atividades propostas no evento? }\end{array}$ & & \\
\hline $\begin{array}{l}\text { Voô teve oportunidade de compartilhar } \\
\text { suas ideias e dúvidas? }\end{array}$ & & \\
\hline $\begin{array}{l}\text { As discussões foram interessantes, } \\
\text { facilitando sua compreensão? }\end{array}$ & & \\
\hline $\begin{array}{l}\text { Como foi seu relacionamento com os } \\
\text { monitores das salas? }\end{array}$ & & & \\
\hline $\begin{array}{l}\text { Como foi o conhecimento demonstrado } \\
\text { pelos monitores das salas? }\end{array}$ & & & \\
\hline Como foi a organização do evento? & & & \\
\hline Como foi o lanche servido? & & & \\
\hline $\begin{array}{l}\text { Você tem interesse em participar de outros } \\
\text { eventos semelhantes? }\end{array}$ & & & \\
\hline Qual a sua impressão final do evento? & & & \\
Qual o assunto que você mais gostou? \\
Qual assunto você não gostou? outro assunto que você gostaria de ver em um próximo evento? Qual? \\
Comentários e sugestões:
\end{tabular}

Fonte: Os autores, 2016.

Analisando as perguntas de múltipla escolha, percebe-se que, de acordo com a avaliação dos participantes (Gráfico 1), a avaliação foi satisfatória, sendo os aspectos avaliados como ótimos em quase sua totalidade. Com relação aos diferentes momentos do evento, destaca-se que o eixo ambiente foi o que teve maior aprovação pelos alunos e professora (Gráfico 2). 


\section{\#tear}

Gráfico 1 - pesquisa de satisfação.

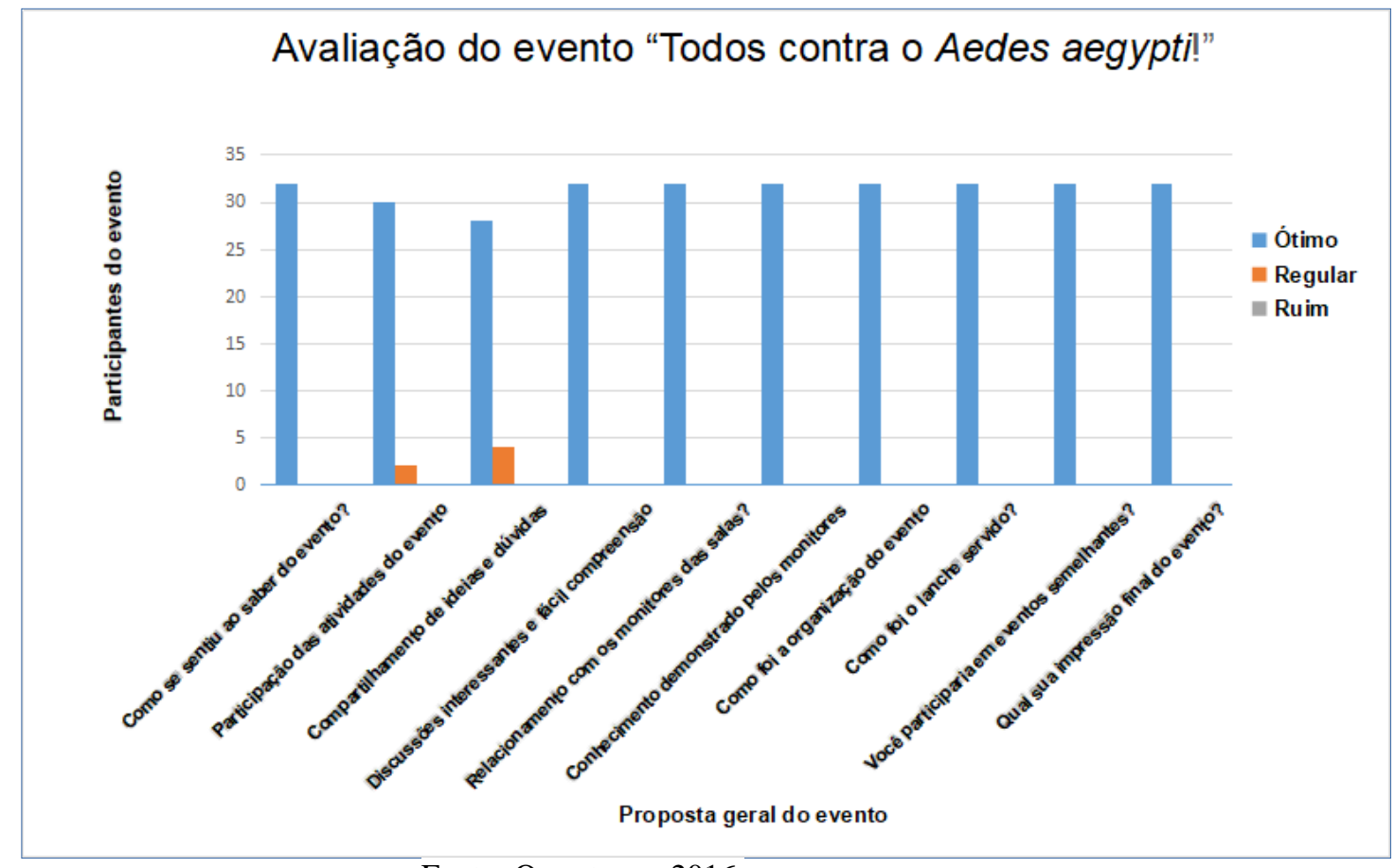

Fonte: Os autores, 2016.

Gráfico 2 - Avaliação dos eixos.

\section{Avaliação do evento "Todos contra o Aedes aegypti!"}

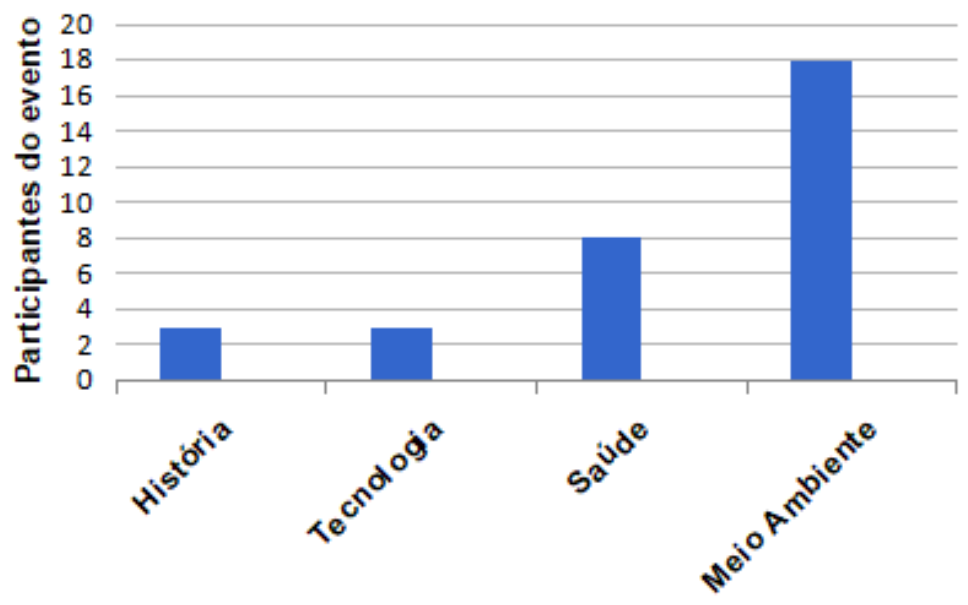

Qual assunto você mais gostou?

- Qual assunto você não gostou?

Eixos temáticos

Fonte: Os autores, 2016. 


\section{\#tear}

Pode-se inferir que um dos motivos para que o eixo meio ambiente tenha sido o mais aceito no evento, tenha sido a possibilidade dos alunos interagiram um com os outros, proporcionado um momento em conjunto entre as diferentes turmas de $7^{\circ}$ ano. A abordagem lúdica colocou os estudantes como protagonistas no processo de ensino-aprendizagem oportunizados. Nesse sentido, revisita-se Rolim (2008), que enfatiza que as atividades lúdicas aumentam o foco e a atenção ao tema proposto e contribuem para que o estudante fortaleça sua relação com o outro. Ainda, destaca que evoca atenção e concentração, ajudando a desenvolver as relações de confiança consigo e com os outros.

\section{Conclusão}

Pelo exposto, conclui-se que o evento no geral foi satisfatório para todos os atores envolvidos, tanto para os estudantes da unidade escolar, quanto para os licenciandos que organizaram o evento, apesar dos desafios ocorridos ao longo do planejamento de execução da ação. Nesse sentido, destacam-se as mudanças do local do evento, devido às dificuldades de mobilidade dos alunos até o local inicialmente programado para a ação, em primeiro momento, o Instituto Federal do Rio Grande do Sul - campus Porto Alegre. Tais dificuldades enfrentadas pelos professores em formação, de certo modo, contribuem para que os mesmos percebam a realidade escolar, e que possam desenvolver estratégias para se adaptarem e resolverem todos os desafios e demandas que o ambiente escolar oferece durante a prática docente.

Também merece destaque a relevância da abordagem sobre a prevenção de doenças, de forma interdisciplinar e contextualizada, envolvendo história, geografia, ciências, saúde, tecnologia e meio ambiente. A escola configura-se em um local onde a promoção de saúde deve constantemente ser valorizada, sobretudo em situações onde as condutas individuais interferem no coletivo, como é o casa das doenças transmitidas pelo mosquito Aedes aegypti, muitas vezes adaptando ao contexto real de vivência de muitos dos estudantes. Além disso, verifica-se a viabilidade para o desenvolvimento de atividades dessa natureza em ambiente escolar, podendo, inclusive, serem abertas à comunidade em geral.

Como reflexão final, verificou-se que a dinâmica ambiental em forma de jogo marcouse como o momento mais prazeroso aos estudantes, demonstrando que ações que promovam a interação e o protagonismo dos alunos pode se tornar um forte aliado para a construção de saberes no ensino de Ciências. 


\title{
USING PLAYFULNESS IN THE TEACHING OF SCIENCE IN A PUBLIC SCHOOL OF PORTO ALEGRE: THE MAKE IN CONTEXTUALIZED AND INTEGRATED TEACHER BEYOND THE CLASSROOM
}

\begin{abstract}
Currently there are several cases related to diseases transmitted by the Aedes aegypti mosquito, reinforcing the validity of its contextualization in science teaching. Aiming to demonstrate to the undergraduate students in the Nature sciences of IFRS the pertinence of using the school space beyond the classroom and training them in organizing scientific events in school units, in 2016, the extension event was developed " All against Aedes aegypti. " The action took place in a public school in Porto Alegre involving two classes of the 7th grade of elementary School and allowed interdisciplinary approaches, contemplating aspects related to history, technology, health and the environment. During the intervention, an environmental dynamics was developed in the form of a game, emphasizing aspects related to the proliferation of the insect. It was based on informative material published by the City of Porto Alegre, researches related to the theme and the use of educational games and production of material tested with undergraduate students. The evaluation by students and teacher Regent of the school unit was considered the best in the event. In addition to addressing the importance of disease prevention, it is perceived the relevance of ludicity, creating moments of interaction, integration, critical development and construction of meaningful and contextualized knowledge related to health and teaching of Sciences.
\end{abstract}

Keywords: Science. Environment. Extension. Playfulness. Aedes.

\section{Referências}

BRASIL. Ministério da Educação. Base Nacional Comum Curricular. Brasília: MEC/SEF, 2017.

. Ministério da Educação. Parâmetros Curriculares Nacionais de $5^{\mathbf{a}}$ a $8^{\mathrm{a}}$ séries: Ciências Naturais. Brasília: MEC/SEF, 1998.

. [Plano Nacional de Educação (PNE)]. Plano Nacional de Educação 2014-2024 [recurso eletrônico]: Lei no 13.005 , de 25 de junho de 2014, que aprova o Plano Nacional de Educação (PNE) e dá outras providências. Brasília : Câmara dos Deputados, Edições. 2014. Câmara, 2014.

FÓRUM DE PRÓ-REITORES DE EXTENSÃO DAS UNIVERSIDADES PÚBLICAS BRASILEIRAS. Plano Nacional de Extensão (1999-2001). Brasília. SESU/MEC, 1999.

GADOTTI, M. A questão da educação formal/não-formal. Sion: Institut Internacional des Droits de $1^{\circ}$ Enfant, p. 1-11, 2005.

GARCIA, J. A Interdisciplinaridade Segundo os Pcns. Rev. de Edu. Pública, Cuiabá, v. 17, n. 35, p. 363-378, 2008.

LEPIENSKI, L.; PINHO, K. E. P. Recursos didáticos no ensino de biologia e ciências: 
Reflexão sobre a utilização de recursos didáticos no ensino de Biologia e Ciências nas escolas públicas da rede estadual de ensino do Paraná. Paraná: UFPR, 2013.

MELLO, D. H. et al. O uso de dinâmicas no ensino de ciências. In: Seminário Institucional do PIBID UNISC, v. 1, p. 1-4, 2015.

OLIVEIRA, V. M. de. Trabalhando a dengue de forma lúdica: os desafios da escola pública paranaense na perspectiva do professor: produções didático-pedagógicas. Cadernos Plano de Desenvolvimento da Escola . v. 2, Paraná, 2013.

ROLIM, A. A. M. et al. Uma leitura de Vygotsky sobre o brincar na aprendizagem e no desenvolvimento infantil. Revista Humanidades, v. 23, n. 2, p. 176-180, 2008.

TRISTAO, M.; FASSARELLA, R. C. Contextos de aprendizagem. In: FERRARO JUNIOR, Luiz Antonio (Org.). Encontros e caminhos: formação de educadoras (es) ambientais e coletivos educadores. Brasília: Ministério do Meio Ambiente, Departamento de Educação Ambiental, 2007, v.2, p. 85-94. 